\title{
Synthesis and Characterization of Lactone Functional Macromonomers by End Group Deactivation and Their Use in Miktoarm Star Polymer
}

\author{
Kadir Demirelli ${ }^{1}$, Feride Bezgin ${ }^{2}$ \\ ${ }^{1}$ Faculty of Science, Department of Chemistry, Universty of Firat, Elazig, Turkey \\ ${ }^{2}$ Faculty of Arts and Sciences, Department of Chemistry, Unıversty of Bitlis Eren, Bitlis, Turkey \\ Email: kdemirelli@firat.edu.tr
}

Received February 29, 2012; revised April 19, 2012; accepted April 28, 2012

\begin{abstract}
Newly designed miktoarm star-shaped copolymers made of poly[(benzyl methacrylate(BMA)-co-( $\varepsilon$-caprolacton)(CL)] and poly[(BMA-b-MMA- $b$-BMA)-co- $\varepsilon$-caprolacton)(CL)] were synthesized by combining ring-opening polymerization (ROP) of $\varepsilon$-caprolactone (CL) and poly(BMA) five membered lacton fuctionalized prepared via atom transfer radical polymerization (ATRP) of BMA, and $\varepsilon$-CL and P(BMA-b-MMA- $b$-BMA) dual functionalized diblock copolymer, in the presence of $\operatorname{tin}(\mathrm{II})$ bis(2-ethylhexanoate) $\left(\mathrm{Sn}(\mathrm{Oct})_{2}\right)$. Although lactone ended poly(benzyl methacrylate) with $\varepsilon$-caprolactone monomer gave ring open polymerization by $\mathrm{Sn}(\mathrm{Oct})_{2}$, the macromonomer itself did not give any polymerization The macromonomers, and the miktoarm star-shaped copolymers were analyzed by FT-IR and ${ }^{1} \mathrm{H}$-NMR spectroscopies and GPC (gel permeation chromatograph), Differential scanning calorimetry (DSC-50) and termogravimetric analysis (TGA-50). These copolymers exhibited the expected structure. The crystallization of star-shaped copolymers was studied by DSC. The results show that when the content of the BMA block increased, the $T_{m}$ of the star-shaped block copolymer increased.
\end{abstract}

Keywords: Miktoarm Star Polymer; Lacton; Ring Open Polymerization

\section{Introduction}

Increasing attention is paid nowadays to the synthesis and characterization of miktoarm star-shaped copolymers that consist of three different polymer chains emanating from a central junction point [1-6]. Generally, starshaped polymers can be prepared by two different routes: the "arm-first" [7] strategy and the "core-first" [8,9] method. In the arm-first approach, the linear arms of the starshaped polymer are synthesized first followed by binding of the arms to form the core. The binding of the arms is achieved by using either a difunctional monomer or a multifunctional terminating agent. The core-first method is based on a multifunctional core used as initiator to initiate the polymerization of monomer to form a multiarm star-shaped polymer [10]. Between the two methods, the core-first approach with multifunctional initiator has received greater attention, since it is easy to control the structure of a star polymer. The "core-first" method has been used in this work to prepare a miktoarm star-shaped copolymer via phloroglucin. Ring-opening polymerization (ROP) [11-13] have been applied to prepare such star-shaped polymers, and the ROP technique has great advantages in preparing well-defined polymers. PCL and its star-shaped polymers are biode-gradable. Therefore, it may have potential applications as biomaterials. Polylactones have potential utility for such usage as a result of their permeability, biocompatibility and biodegradability [14]. One of the convenient strategies in synthesizing these polymers is the ring opening polymerization of the corresponding cyclic lactone monomers or functionally related compounds $[15,16]$. In recent years, attention on synthesis of star-shaped PCL and star-shaped block copolymers with PCL as their arms has been increasing. For example, Rieger et al. [6] reported controlled synthesis of an ABC Miktoarm Star-Shaped Copolymer by sequential ring-opening polymerization of ethylene oxide, benzyl $\beta$-Malolactonate, and $\varepsilon$-Caprolactone. Thus, they have designed as a macroinitiator for the sequential synthesis of two biocompatible/biodegradable polyesters, i.e., poly(benzyl $\beta$-malolactonate) (PMLABz) and poly $(\varepsilon$-caprolactone) (PCL) consisting of biocompatible/bioresorbable arms. Lele et al. [17] have reported the synthesis of star-shaped poly( $\varepsilon$-caprolactone)-b-poly(N-(2hydroxypropyl)methacrylamide) by combination of ringopening and chain transfer polymerization. Also, Chen et 
al. [18] have reported newly designed star-shaped block copolymers made of poly( $\varepsilon$-caprolactone) ( $\varepsilon$-PCL) and polystyrene (PS). Hedrick et al. [19] have also contributed to this field with their dendrimer-like block copolymer which was obtained upon combining ring-opening polymerization of $\varepsilon$-caprolactone for the inner part and ATRP of methyl methacrylate for the external branches. The polymerization of $\varepsilon$-caprolacton is commonly initiated by alcohols in the presence of a tin catalysts [20,21].

In this paper, we focused on the synthesis of miktoarm star copolymers using "core-first" method by ringopening (ROP) process using appropriate (co)polymers with poly(benzyl methacrylate) lacton functionalized and P(BMA-b-MMA- $b$-BMA) dual functionalized diblock copolymer as macromonomer. Thus, the first aim of our study was to synthesize suitable macroinitiators. Lowmolecular-weight poly(benzyl methacrylate) one and P(BMA-b-MMA- $b$-BMA) dual functionalized diblock copolymer prepared by atom transfer radical polymerization (ATRP) of benzyl methacrylate at $110^{\circ} \mathrm{C}$ was used as starting materials for ring open polymerization. Then, the ROP of $\varepsilon$-caprolacton with one and dual functionalized macromonomers was carried out in the presence of tin(II)bis(2-ethylhexanoate) $\left(\mathrm{Sn}(\mathrm{Oct})_{2}\right)$ at $130^{\circ} \mathrm{C}$.

\section{Experimental Section}

\subsection{Materials}

MMA was vacuum-distilled after washing with a 5\% $\mathrm{NaOH}$ aqueous solution just before homopolymerization. Cuprous(I) bromide, 2,2'-bipyridyne (bpy), and ethyl 2-bromoacetate (analytical reagent) were used as received. 2-Chloroacetyl chloride (Aldrich, 99\%) was used as received. The $\varepsilon$-caprolactone (CL, Aldrich) was stirred with $\mathrm{CaH}_{2}$ overnight at $80^{\circ} \mathrm{C}$ and then distilled under vacuum. Phloroglucin dihydrate (Aldrich) was dryed to remove dihydrat in vacuo (at $2 \mathrm{mmHg}$ ) at $120^{\circ} \mathrm{C}$. Benzyl methacrylate (BMA) was prepared by aid of literature [22]. So, BMA was synthesized by the reaction of benzyl alcohol and methacryloyl chloride at $60^{\circ} \mathrm{C}-70^{\circ} \mathrm{C}$ by using potassium carbonate. It was distilled in vacuo (b.p.: $103^{\circ} \mathrm{C}$ at $2 \mathrm{mmHg}$ ).

\subsection{Synthesis of 7-Hydroxy-4-chloromethyl Coumarin (CIMOHC)}

Synthesis of 7-hydroxy-4-chloromethylcoumarin was prepared as follows [23].

To resorcinol (1.1 g, $10 \mathrm{mmol})$ stirring in concentrated $\mathrm{H}_{2} \mathrm{SO}_{4}(20 \mathrm{ml})$ and ethyl acetoacetate $(1.3 \mathrm{~g}, 10 \mathrm{mmol})$ was added. The mixture was stirred for $10 \mathrm{~h}$ at room temperature, then poured into water $(100 \mathrm{ml})$ and left to stand overnight. The corresponding 7-hydroxy-4-chloromethyl coumarin was precipitated and was recovered by filtration and then purifided using 9:1 n-hexane/ethylacetate as eluent.

${ }^{1} \mathrm{H}-\mathrm{NMR}(\delta, \mathrm{ppm}): 4.89\left(\mathrm{~s},{ }^{2} \mathrm{H}, \mathrm{CI}-\mathrm{CH}_{2}-\right), 6.40\left(\mathrm{~s},{ }^{1} \mathrm{H}\right.$, olefinic proton on coumarin), 6.79 and 6.91 (protons on 5 and 6 carbons in aromatic ring), $7.71\left(\mathrm{~s},{ }^{1} \mathrm{H}\right.$, between two rings coumarin group).

${ }^{13} \mathrm{C}-\mathrm{NMR}$ ( $\delta$, ppm): $41.3\left(\mathrm{CI}-\mathrm{CH}_{2}-\right), 126.2,112.9,111.6$, $110.1,102.8$ (carbons with hydrogen on cou- marin)

\subsection{Synthesis of 4-(Chloromethyl)-2-oxo-2H-chromen-7-yl Chloroacetate (CMOCA)}

4-(Chloromethyl)-2-oxo-2H-chromen-7-yl chloroacetate was prepared as follows [24,25]. 7-Hydroxy-4-chloromethy-lcoumarin $(2.1 \mathrm{~g}, 0.01 \mathrm{~mol})$, triethylamine $(1.01 \mathrm{~g}$, $0.01 \mathrm{~mol})$, and tetrahydrofuran $(20 \mathrm{~mL})$ were added into a $100 \mathrm{~mL}$-round-bottom flask equipped with a magnetic stirrer. After cooling to $0^{\circ} \mathrm{C}$ with an ice bath, a solution of a chloroacetylchloride $(1.13 \mathrm{~g}, 0.01 \mathrm{~mol})$ in $5 \mathrm{~mL}$ of tetrahydrofurane dryed was added dropwise. The reaction mixture was then stirred at room temperature for additional $24 \mathrm{~h}$, and the salt formed in the reaction was filtered off. The filtrate was washed with $\mathrm{NaHCO}_{3}$ solution and following by water until neutralization, and the solution was dried over $\mathrm{MgSO}_{4}$. After filtration, the solvent was removed by rotary evaporator, and then purifided using 9:1 hexane/ethylacetate as eluent.

${ }^{1} \mathrm{H}$ NMR of CMOCA $(\delta, \mathrm{ppm}): 4.34\left(\mathrm{~s},{ }^{2} \mathrm{H},-\mathrm{CH}_{2}-\mathrm{CI}\right)$, $4.65\left(\mathrm{~s},{ }^{2} \mathrm{H},-\mathrm{C}(=\mathrm{O}) \mathrm{CH}_{2}-\mathrm{CI}\right), 6.55\left(\mathrm{~s},{ }^{1} \mathrm{H} 8\right.$ on aromatic ring, 7.15 (6 on aromatic ring) 7.69 (5 on aromatic ring).

\subsection{Characterization}

${ }^{1} \mathrm{H}$ NMR spectra were recorded on a Bruker AVENCE400 nuclear magnetic resonance (NMR) instrument with $\mathrm{CDCl}_{3}$ as solvent and tetramethylsilane (TMS) as internal standard. Infrared spectra were obtained on a Perkin Elmer Spectrum one FT-IR spectrometer.

Thermogravimetric analysis (TGA) measurements were carried out under a nitrogen flow with a TGA-50 thermobalance at a heating rate of $10^{\circ} \mathrm{C} \mathrm{min}^{-1}$. Differential scanning calorimetry (DSC) thermograms of polymers were measured by DSC-50. The molecular weight and molecular weight distribution of the polymers were measured at $30^{\circ} \mathrm{C}$ on a Agilient 1100 gel permeation chromatography (GPC) equipped with microstyragel columns and detector. Molecular weights were calibrated against narrowed polymethylmethacrylate standards. THF was used as eluent at a flow rate of $1.0 \mathrm{~mL} / \mathrm{min}$.

\subsection{Synthesis of Lacton Functionalized Macromonomer by ATRP Method}

The ATRP reaction of lacton functionalized macromo- 
nomer was carried out according to procedure recorded in literatur [22].

\subsection{Synthesis of Poly(Methyl Methacrylate) Ended 7-Hydroxy Coumarin by ATRP Method}

The dried polymerization tube was charged with $\mathrm{CuBr}$ (14.4 mg, $0.1 \mathrm{mmol}$ ), 2,2'-bibyridine (31.2 $\mathrm{mg}, 0.2 \mathrm{mmol}$ ), 7-hydroxy-(4-chloromethyl)coumarin (21 mg, $0.1 \mathrm{mmol})$ and passed from Ar gas. Then, the methyl methacrylate ( $1 \mathrm{gr}, 10 \mathrm{mmol}$ ) was added into polymerization tube. The tube was sealed under vacuum after three freze-pumpthaw cycles, and the sealed tube was immersed into an oil bath at $110^{\circ} \mathrm{C}$. After $12 \mathrm{~h}$, the polymerization mixture was cooled to ambient room and precipitated three times in ethyl alcohol containing $1 \%$ HCI solution. The resultant product was dried in a vacuum oven at $40^{\circ} \mathrm{C}$ for $24 \mathrm{~h}$.

\subsection{Synthesis of Dual Lacton Functionalized Macromonomer}

The 4-[(PMMA)methyl)]-2-oxo-2H-chromen-7-yl chloroacetate (CAPMMA) was synthesized by reaction of 7-hydroxy-[(4-PMMA)methyl]coumarin (HAPMMA) and chloroacetyl chloride by using CIMOHC as initiator in ATRP in presence of triethy-lamine at $0^{\circ} \mathrm{C}-5^{\circ} \mathrm{C}$. The CAPMMA was used in synthesis of macromonomer dual lacton funtionalized. For this purpose, the dried polymerization tube was charged with $\mathrm{CuBr}(7.2 \mathrm{mg}, 0.05$ mmol), 2,2'-bipyridine (315.6 g, $0.1 \mathrm{mmol}),(\mathrm{Mn}=4000$ gr/mol; $315 \mathrm{mg}, 0.05 \mathrm{mmol}$ ) and passed from Ar gas. Then, benzyl methacrylate $(0.88 \mathrm{gr}, 5 \mathrm{mmol})$ was added into the polymerization tube. The tube was sealed under vacuum after three freze-pump-thaw cycles, and the sealed tube was immersed into an oil bath at $110^{\circ} \mathrm{C}$. After $72 \mathrm{~h}$, the polymerization mixture was cooled to ambient room and precipitated three times in cooled ethylalcohol. The resultant product was dried in a vacuum oven for 24 h at $40^{\circ} \mathrm{C}$.

\subsection{Synthesis of Three Armed Miktoarm Star Shaped Copolymer from Macromonomer with $\varepsilon$-Caprolacton}

Phloroglucin $(0.001 \mathrm{~mol})$, monomer $(\varepsilon$-CL) $(0.06 \mathrm{~mol})$, macromonomer (poly(BMA) ended lacton) and stannous octoate $\left(7.5 \times 10^{-6} \mathrm{~mol}\right)$ were added under nitrogen in previously flamed and argon-purged schlenk tube equipped with magnetic stirrer. The ring opened polymerization of $\varepsilon$-CL was carried out in bulk at $130^{\circ} \mathrm{C}$. After $48 \mathrm{~h}$, the polymerization was terminated by cooling the tube to the room temperature, then diluted with $\mathrm{CH}_{2} \mathrm{Cl}_{2}$ and poured into $\mathrm{n}$-hexane. The resulting polymer was dryed at $30^{\circ} \mathrm{C}$ in a vacuum for 2 days.

\section{Results and Discussion}

Our strategy for the synthesis of lacton functional macromonomers by end group deactivation during ATRP of benzyl methacrylate was to design miktoarm star copolymers with $\varepsilon$-caprolacton (Scheme 1).

The linear poly(benzyl methacrylate) lacton ended was synthesized by ATRP method at $110^{\circ} \mathrm{C}$ with $\mathrm{CuBr}$ (0.1 mmol), 2,2'-bibyridine $(0.2 \mathrm{mmol})$ and ethyl 2-bromoacetate as initiator. The FT-IR and ${ }^{1} \mathrm{H}-\mathrm{NMR}$ spectra of poly(BMA) obtained via ATRP are shown in Figures 1(a) and 2(a), respectively. The strong band at $1730 \mathrm{~cm}^{-1}$ is the stretching vibration of the carbonyl group in ester, and the bands at $1162 \mathrm{~cm}^{-1}$ and $1253 \mathrm{~cm}^{-1}$ are symmetric stretching and asymmetric stretching of the $-\mathrm{C}(=\mathrm{O})-\mathrm{O}-\mathrm{C}$ group, respectively. The intensity band at $1779 \mathrm{~cm}^{-1}$ showed a lactone ring with five members. It may be suggested that a lactone ring forms by means of removing benzyl bromide at the chain end, as suggested in Scheme 2. This band is not observed in that of poly(BMA) synthesized under free-radical polymerization conditions [22]. Designed miktoarm star shaped copolymers made of poly[( $\varepsilon$-caprolacton $)(\varepsilon$-PCL)-cobenzyl methacrylate(BMA)] were synthesized by combining ring-opening polymerization (ROP), as was illustrated in Scheme 3.

The structure of copolymer synthesized was characterized by FT-IR (Figure 1(b)) and ${ }^{1} \mathrm{H}-\mathrm{NMR}$ (Figure 2(b)) spectra. The FT-IR spectrum of miktoarm star shaped poly[( $\varepsilon$-caprolacton)(PCL)-co-benzyl methacrylate (BMA) prepared from ring opened not showed the band at $1779 \mathrm{~cm}^{-1}$, which characterizes lacton ring. Disappearance of this band is an important evidence of ring open for poly(BMA) lacton ended as macromonomer at $130^{\circ} \mathrm{C}$. The ${ }^{1} \mathrm{H}$ NMR spectrum of poly(BMA) by ATRP are illustrated in Figure 2(a), and the formation reaction of miktoarm star copolymer is showed in Scheme 1. The peaks at $7.16-7.32 \mathrm{ppm}$ reveal the phenyl ring and the signal at $4.92 \mathrm{ppm}$ assigned to methylene is adjacent to oxygen in the BMA unit, the signal at 5.18 ppm was assigned to methylene protons of benzyl group on lacton ring. This demonstrates that the PBMA ended lacton group has completely been copolymerized with $\varepsilon$-CL. But this band did not disappear in only ROP of poly (BMA) lacton ended. So, although poly(benzyl methacrylate) ended lactone with $\varepsilon$-caprolacton shows ring open polymerization by $\mathrm{Sn}(\mathrm{Oct})_{2}$, poly(benzyl methacrylate) lactone ended did not show ring opening reaction. This is probably due to that unsubstitued cyclic esters activated by $\mathrm{Sn}(\mathrm{Oct})_{2}$ are attacked by nucleophiles like hydroxyl groups, but because of steric hinder of substituents on lacton ring is not activated by $\mathrm{Sn}(\mathrm{Oct})_{2}$. 
The most reliable method to determine the actual molar mass or composition of such copolymers is by ${ }^{1} \mathrm{H}-$ NMR. The copolymer composition of the miktoarm star shaped P(BMA-co- $\varepsilon$-CL) was determined based on the integral values of the separate signals, which are chara- cteristic for BMA and $\varepsilon$-CL moiets at $4.86 \mathrm{ppm}(20 \mathrm{~mm})$ and $4.05 \mathrm{ppm}(2.1 \mathrm{~mm})$, respectively, The copolymer compositions by using the integration values of the separate signals, can be calculated according to following equation:<smiles>[Y1]C(C)(CC(C)(CCCC(=O)OCC)C(=O)OCc1ccccc1)C(=O)OC1(C)CC(C)(C(=O)OCc2ccccc2)OC1=O</smiles>

n
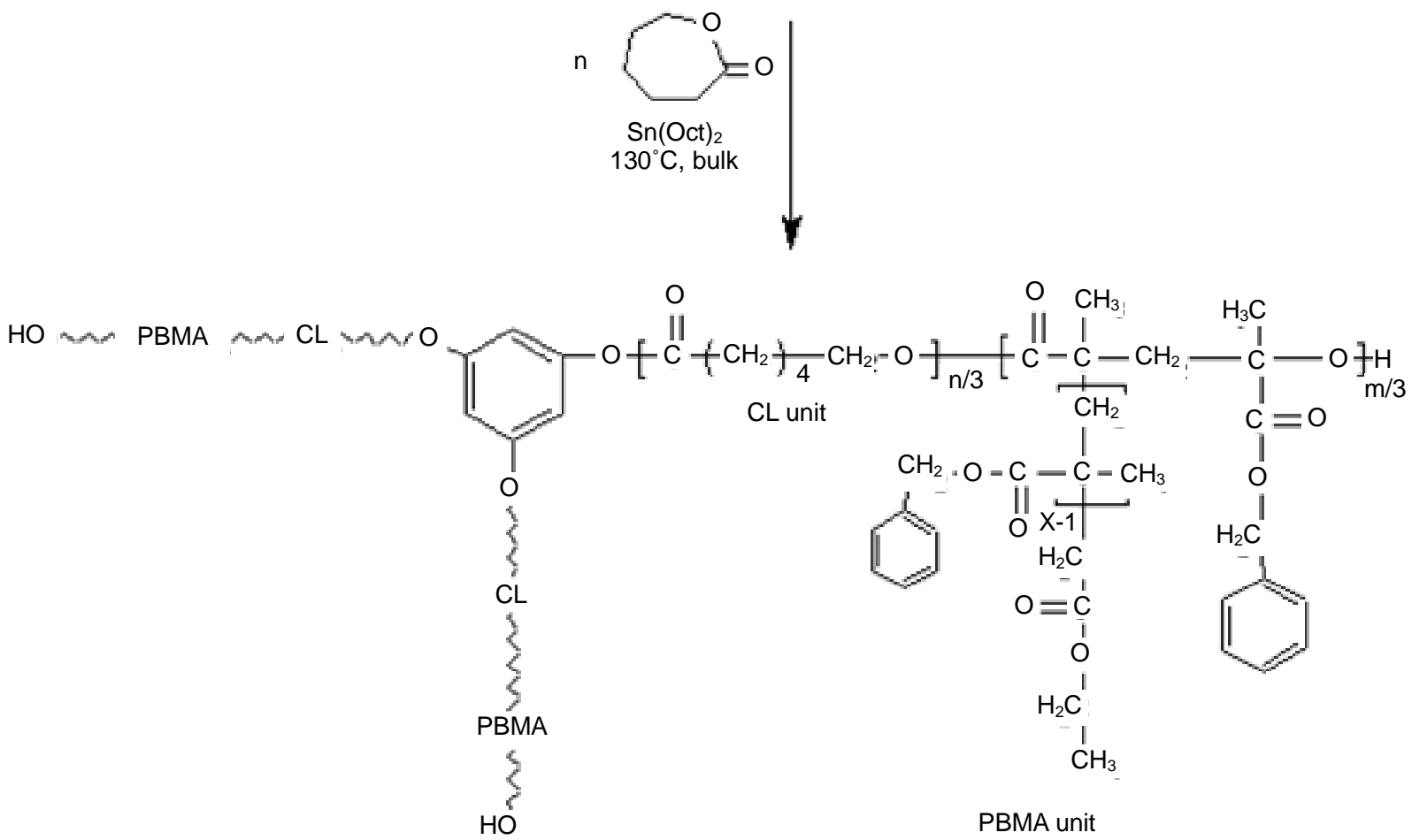

Scheme 1. The structure of miktoarm star shaped poly( $\varepsilon$-CL-co-BMA).<smiles>C=C(C)C(=O)OCc1ccccc1</smiles>

Scheme 2. The structure of lacton functionalized poly(BMA) [22]. 
<smiles>C=C(C)C(=O)OCc1ccccc1</smiles>

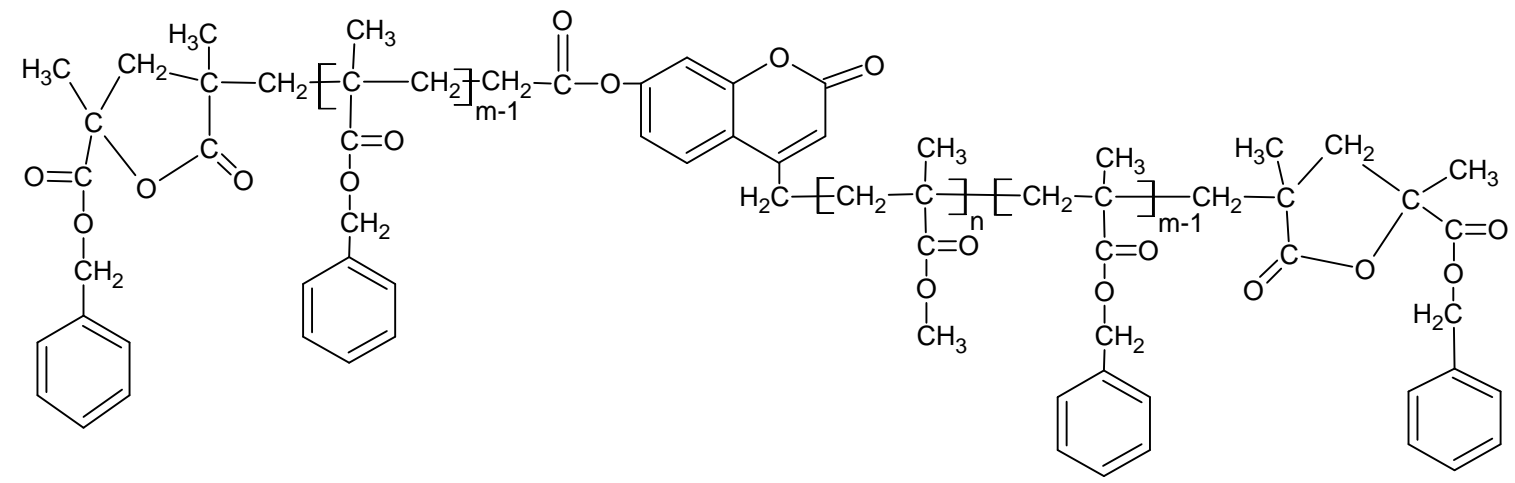

Scheme 3. The reaction of P(BMA-b-MMA-b-BMA) dual functionalized diblock copolymer.

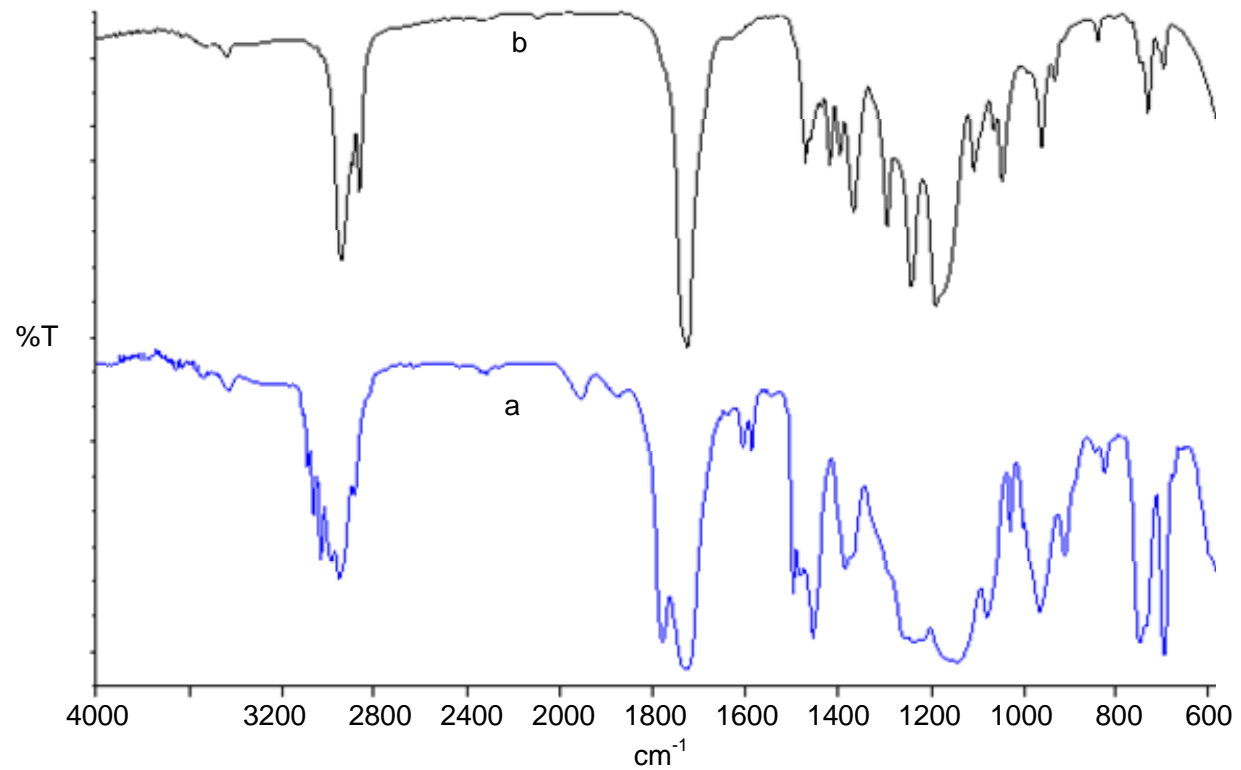

Figure 1. FT-IR spectra of (a) Poly(BMA) ended lacton obtained by ATRP method (b) Miktoarm star shaped P(BMA-co- $\varepsilon$-CL) obtained by ring opened polymerization of poly(BMA) ended lacton with $\varepsilon$-CL. 


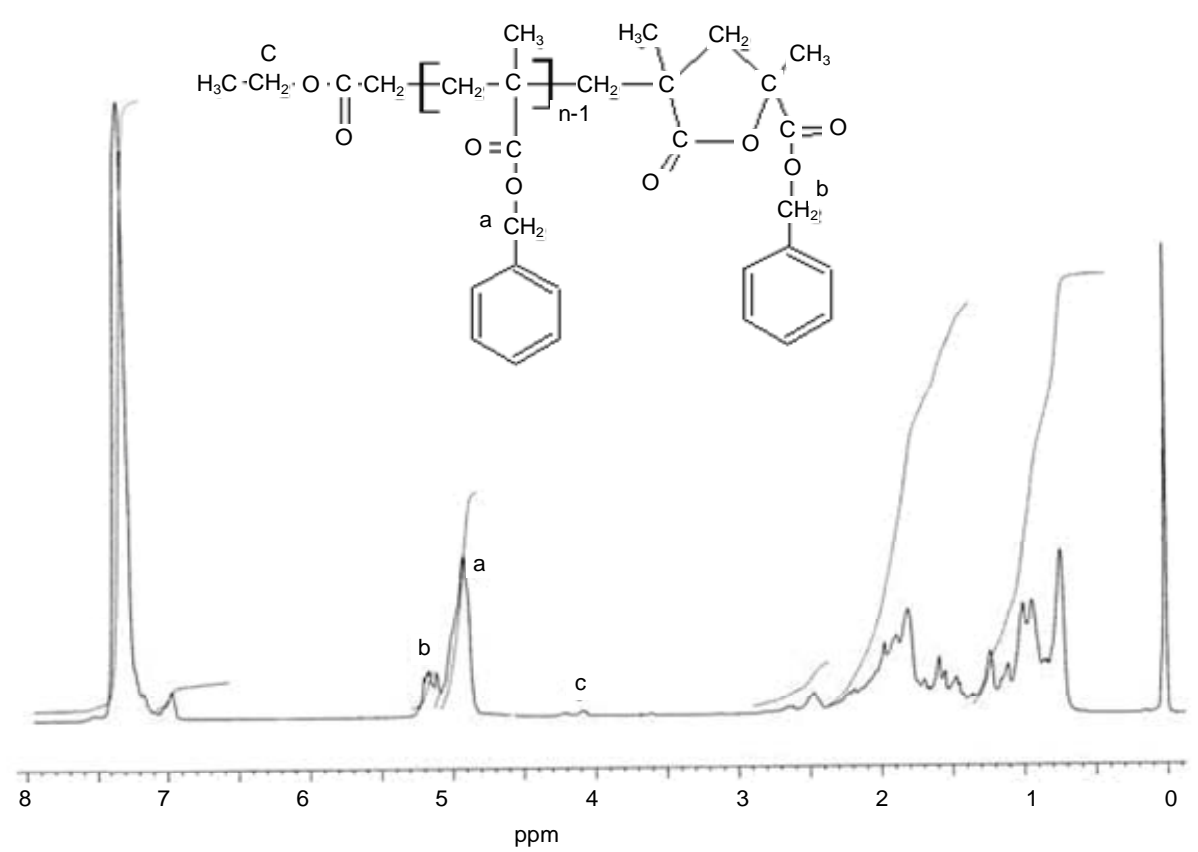

(a)

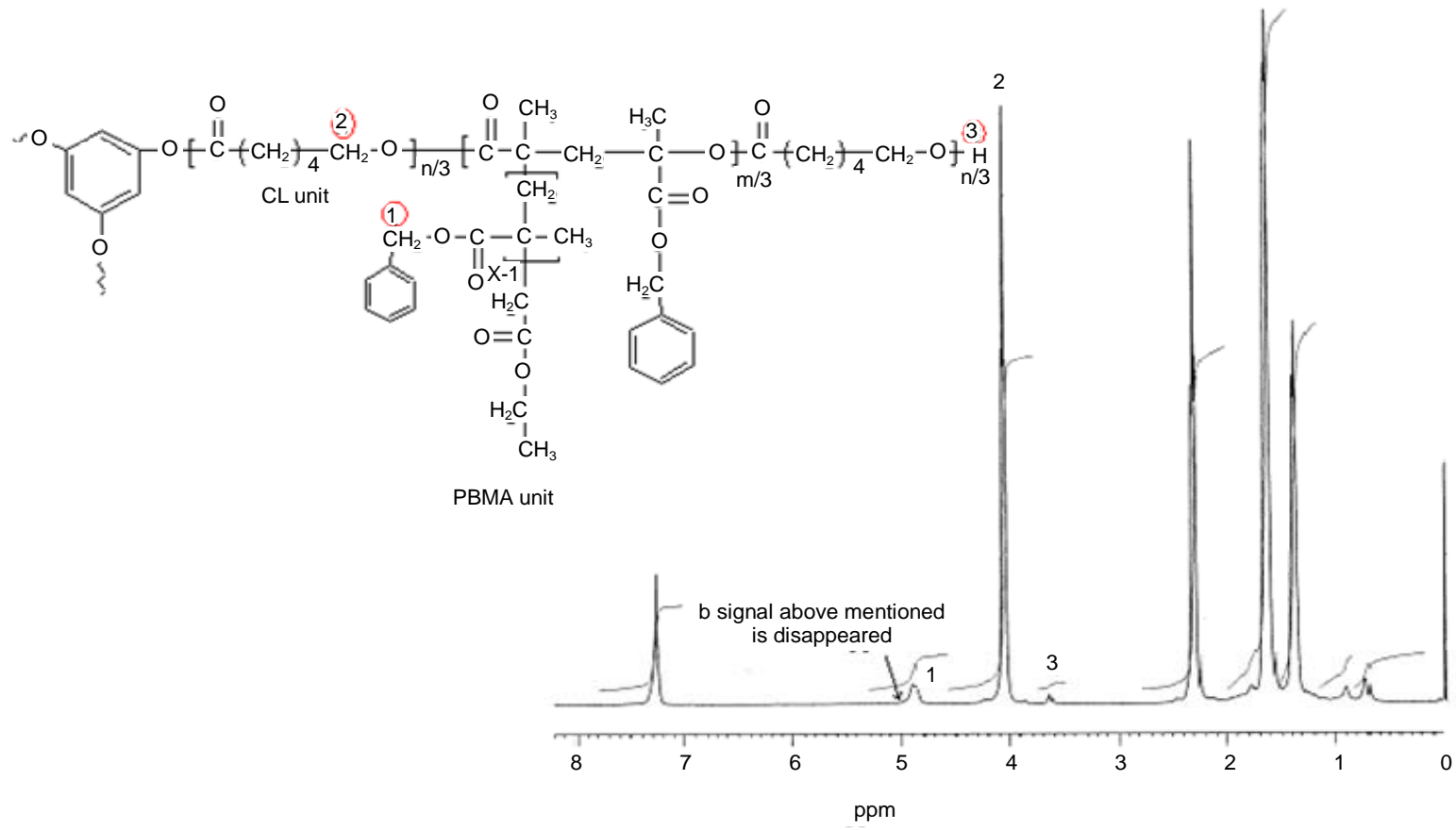

(b)

Figure 2. ${ }^{1}$ H-NMR spectra of a) Poly(BMA) ended lacton by prepared ATRP method; b) Miktoarm star shaped poly(BMAco- $\varepsilon-\mathrm{CL})$.

$$
C=\frac{\int \text { height of } \mathrm{CH}_{2} \text { protons in BMA units }}{\int \text { height of } \mathrm{CH}_{2} \mathrm{OC} \text { - protons in MMA units }}=\frac{2 m_{1}}{2 m_{2}}
$$

On simplification; $m_{1}=\frac{C}{C+1}$

where $m_{1}$ and $m_{2}$ are the molar fractions of BMA and $-\varepsilon$-CL in the copolymer, with lacton end group. Copolymer compositions of BMA and $-\varepsilon$-CL were determined as $9.5 \%$ and $90.5 \%$, respectively.

The copolymer composition of P(BMA-b-MMA- $b$ BMA) dual functionalized diblock copolymer was determined based on the integral values of the separate signals, which are characteristic for MMA and BMA moiets at $3.63 \mathrm{ppm}$ and $4.89 \mathrm{ppm}$, respectively, The copolymer compositions by using the integration values of the separate signals, can be calculated according to following equation: 


$$
C=\frac{\int \text { height of } \mathrm{CH}_{2} \text { protons in BMA units }}{\int \text { height of } \mathrm{CH}_{3} \text { protons in MMA units }}=\frac{2 m_{1}}{3 m_{2}}
$$

On simplification; $m_{1}=\frac{3 C}{3 C+2}$

where $m_{1}$ and $m_{2}$ are the molar fractions of BMA and MMA in the copolymer, with lacton end group. Copolymer compositions of MMA and BMA were determined as $68 \%$ and $32 \%$, respectively.

The number-average molecular weight $\left(M_{n, \mathrm{NMR}}\right)$ of poly(BMA) ended lacton has been calculated by following equation :

$$
\begin{aligned}
& M_{n, \mathrm{NMR}}(\mathrm{PBMA} \text { ended lacton }) \\
& =\left(I_{4.91} / I_{5.18}\right) \times M_{\mathrm{BMA}}=(1.80 / 0.18) \times 176=1780
\end{aligned}
$$

The polymerization of $\varepsilon$-caprolacton is commonly initiated by alcohols in the presence of a tin catalysts [20,21]. Some groups of authors [26-28] advanced schemes in which cyclic esters activated by $\mathrm{Sn}(\mathrm{Oct})_{2}$ are attacked by nucleophiles like hydroxyl groups coming from the chain ends and reforming the unit terminated with $-\mathrm{OH}$. Two of groups cited above proposed detailed chemistry in which a secondary oxonium ion appears. The schemes mentioned above strikingly differs from the one in which tin atoms are becoming a part of the active species at the growing polymer chain-end [29].

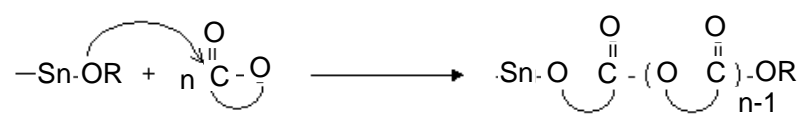

Poly(MMA) 7-(chloroacetoxyloxy) coumarin ended (CAPMMA) was prepared from reaction of poly(MMA) 7-hydroxy coumarin ended (HAPMMA) with chloroacetylchloride in presence of triethyl amin. Figure 3 shows a typical ${ }^{1}$ HNMR spectrum of HAPMMA (a in Figure 3) and CAPMMA (b in Figure 3). It cleraly shows that besides the typical signals of coumarin group, which is the end group of PMMA chain at $8.3 \mathrm{ppm}(\delta \mathrm{H}$ (a)), $3.7 \mathrm{ppm}(\delta \mathrm{H}(\mathrm{b}))-\mathrm{OCH}_{3}$ next to chloride, which is on the other end group of PMMA chains, and $3.6 \mathrm{ppm}$ $(\delta \mathrm{H}(\mathrm{e}))$ is characteristic for $\mathrm{CH}_{3}$ protons of MMA units repeating. Otherwise, when a in Figure 3 compared with $\mathrm{b}$ in Figure 3, it is seen that the terminal $\mathrm{CI}-\mathrm{CH}_{2} \mathrm{C}=\mathrm{O}$ methylene (g) signals of the macroinitiator (HAPMMA) at $4.27 \mathrm{ppm}$. c in Figure 3 shows ${ }^{1} \mathrm{H}-\mathrm{NMR}$ spectrum of poly(BMA-b-MMA- $b$-BMA) ended dual lacton. The signals of $4.95 \mathrm{ppm}$ represents $-\mathrm{OCH}_{2}-$ (peak $\mathrm{h}$ ), the signals at $5.18 \mathrm{ppm}$ represents $-\mathrm{OCH}_{2}-\mathrm{Ar}$ (peak i) on lacton group. The signals at 3,6 ppm represents $\mathrm{CH}_{3}$ (peak k) in MMA units. The F T-IR spectra of poly(methyl methacrylate) ended 7-hydroxy coumarin, poly(MMA) 7-(chloracetoxyloxy) coumarin ended (CAPMMA), $\mathrm{p}$ (BMA-b-MMA- $b$-BMA) dual functionalized diblock copolymer and miktoarm star shaped poly[( $\varepsilon$-caprolacton $)$ (PCL)-co-(BMA-b-MMA- $b$-BMA)] were showed in Figure 4. The most characteristic bands for HAPMMA (a in Figure 4) are at $3450 \mathrm{~cm}^{-1}(\mathrm{OH}$ strettching) and 1730 $\mathrm{cm}^{-1}(\mathrm{C}=\mathrm{O})$. Incorporation to HAPMMA of chloroacetyl groups was further evidenced as a shoulder by $1758 \mathrm{~cm}^{-1}$ for $\mathrm{C}=\mathrm{O}\left(\mathrm{CI}-\mathrm{CH}_{2} \mathrm{C}=\mathrm{O}\right) \mathrm{b}$ in Figure 4 . Figure 4 (c) shows FT-IR spectrum of $\mathrm{p}$ (BMA-b-MMA- $b$-BMA) dual functionalized diblock copolymer. The strong band at 1731 $\mathrm{cm}^{-1}$ is due to the stretching vibration of the ester carbonyl group in both MMA and BMA units. The bands at $1162 \mathrm{~cm}^{-1}$ and $1253 \mathrm{~cm}^{-1}$ are symmetric stretching and asymmetric stretching of the $-\mathrm{C}(=\mathrm{O})-\mathrm{O}-\mathrm{C}$ group, respectively. The intensity band at $1775 \mathrm{~cm}^{-1}$ showed a lactone ring with five members. It may be suggested that a lactone ring forms by means of removing benzyl bromide at the chain end, as suggested in Scheme 4. The FT-IR spectrum of miktoarm star shaped poly[(BMAb-MMA- $b$-BMA)-co- $\varepsilon$-CL)] synthesized from ring opened copolymerization of $\mathrm{p}$ (BMA-b-MMA- $b$-BMA) dual lacton functionalized with $\varepsilon$-caprolacton at $130^{\circ} \mathrm{C}$ not showed the band at $1779 \mathrm{~cm}^{-1}$, which characterizes $\mathrm{C}=\mathrm{O}$ in lacton ring with five members. This phenomen shows that lacton groups form copolymer with $\varepsilon$-CL. The ${ }^{1} \mathrm{H}$ NMR spectrum of miktoarm star shaped poly[(BMA-bMMA-b-BMA]-co- $\varepsilon$-CL] showed peaks at 7.16 - 7.32 ppm reveal the phenyl ring and the signal at $4.92 \mathrm{ppm}$ assigned to methylene is adjacent to oxygen in the BMA unit, and not showed the signal at 5.18, which characterizes methylene of benzyl group on lacton ring. This is an other important evidence of ring open for lacton group of $\mathrm{p}$ (BMA-b-MMA- $b$-BMA) dual lacton functionalized during copolymerization with $\varepsilon$-CL.

\subsection{GPC Measurements}

The average molecular weights of the poly(BMA), three armed $\varepsilon$-PCL and their copolymers in THF were determined by GPC calibrated using poly(methyl methacrylate) standards, and the single GPC traces of the poly (BMA) and all the star shaped homo andcopolymers are showed in Figures 5 and 6. Figure 5 shows the typical GPC curves of poly(BMA) ended lacton (a curve in Figure 5), miktoarm star shaped $\mathrm{P}(\mathrm{BMA}-\mathrm{co}-\varepsilon-\mathrm{CL})$ (b curve in Figure 5) were showed as compared with those of original star-shaped PCL. The $M_{n}$ and polydispersity for P(BMA) ended lacton by ATRP method are 2900 and 1.20 , respectively. Those of miktoarm star shaped $\mathrm{P}$ (BMA-co- $\varepsilon$-CL) are 8600 and 1.24 , respectively. In this case, the GPC trace of miktoarm star shaped P(BMA-co$\varepsilon$-CL) shows a very signifficant shift to higher molecular weights as compared to lineear poly(BMA), providing that the new polymer was readily formed. In Figure 5, the GPC traces of the starting poly(BMA) is also presented. 


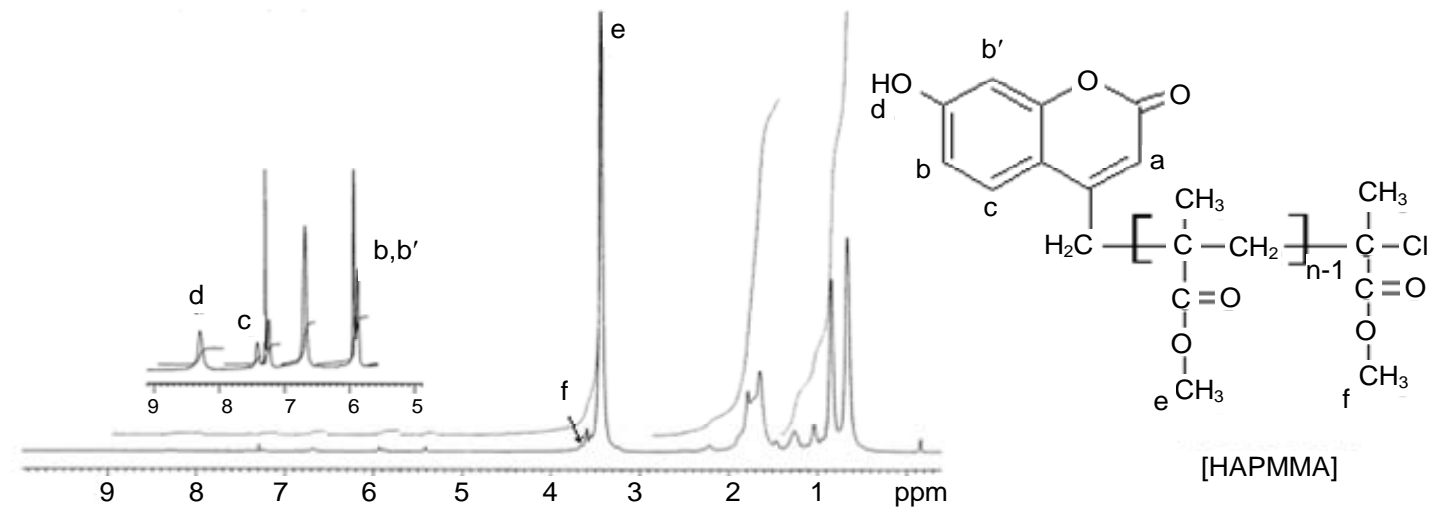

(a)

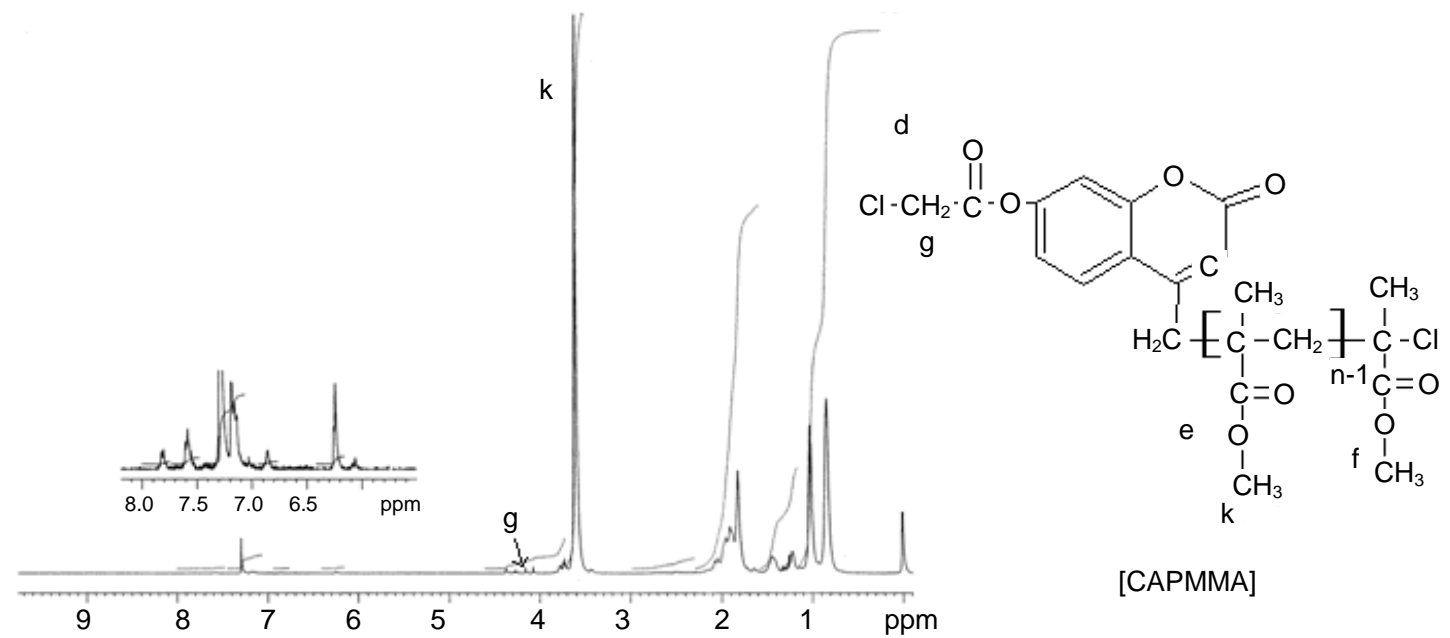

(b)

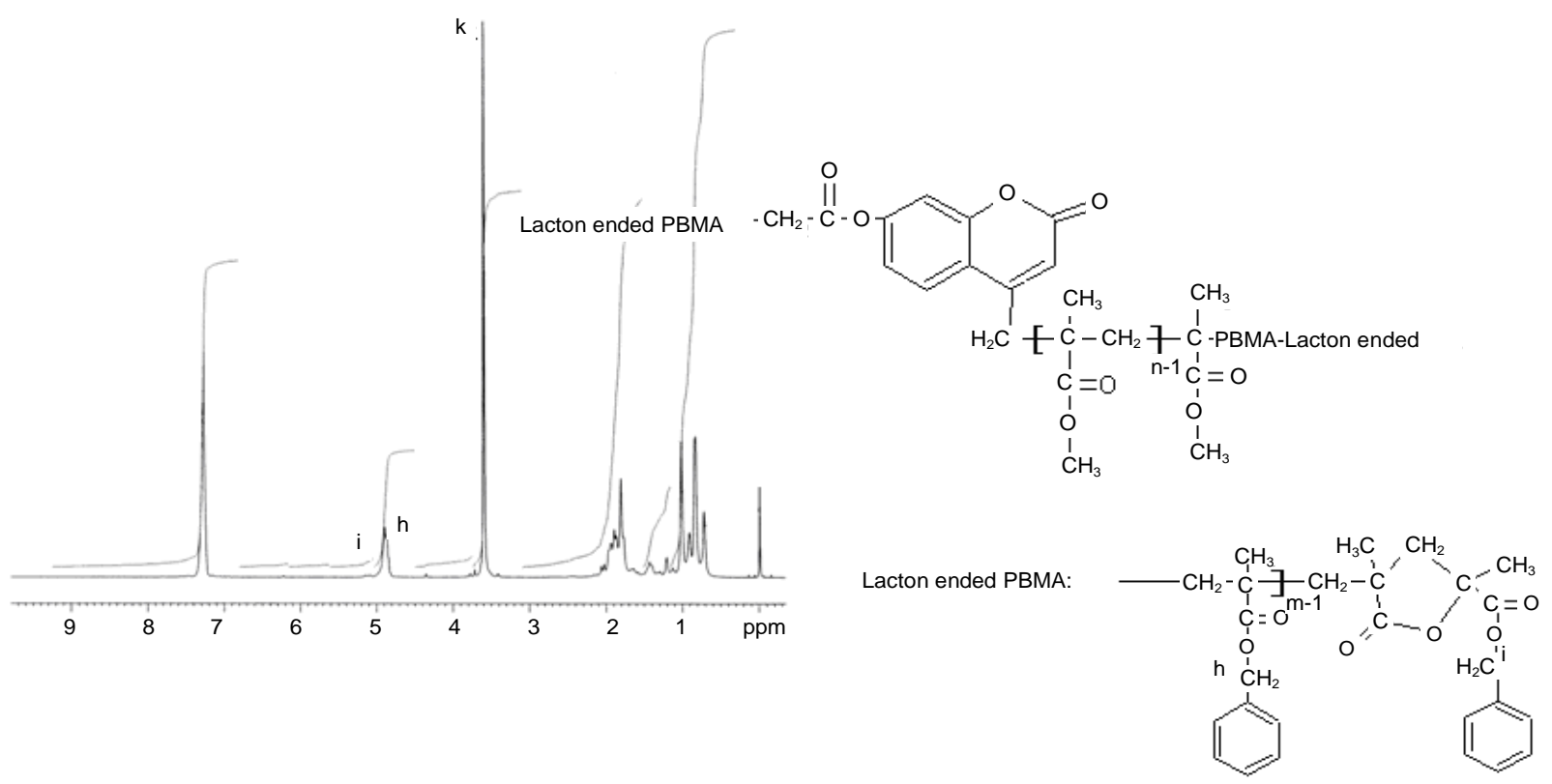

(c)

Figure 3. ${ }^{1}$ H-NMR spectra of (a) Poly(MMA) 7-hydroxy coumarin ended (HAPMMA); (b) Poly(MMA) 7-(chloracetoxyloxy) coumarin ended (CAPMMA); (c) P(BMA-b-MMA-b-BMA) dual functionalized diblock copolymer. 


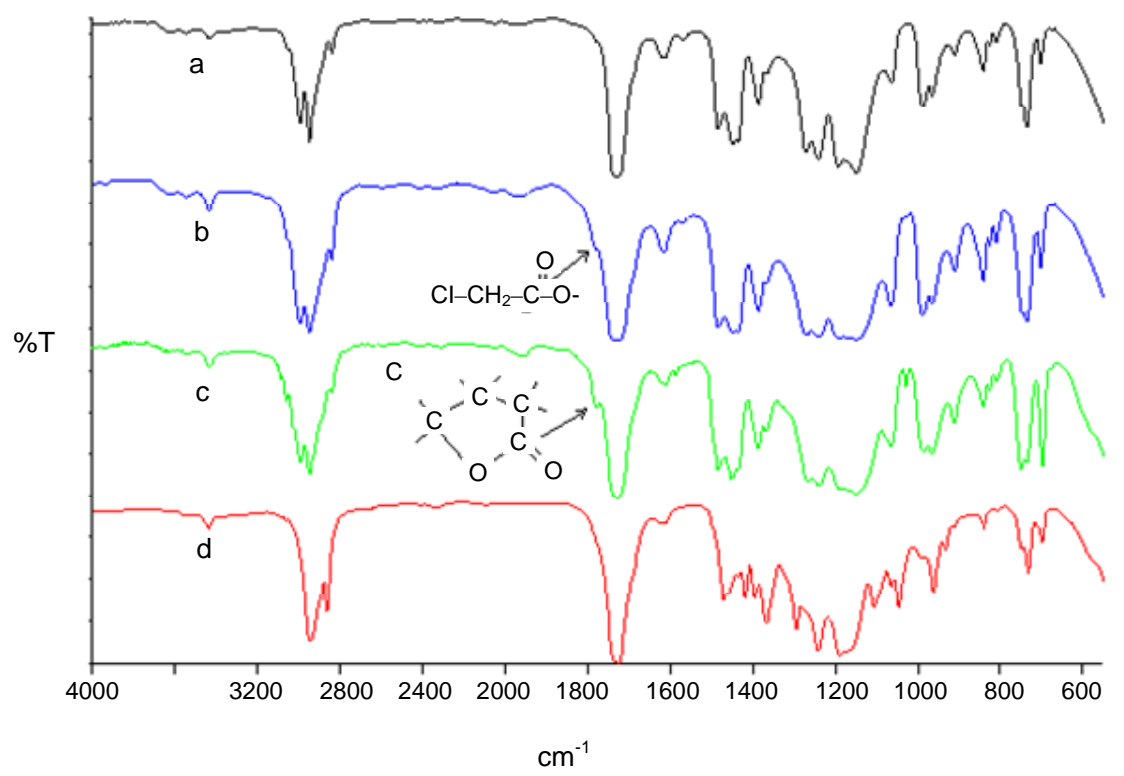

Figure 4. F T-IR spectra of (a) Poly(methyl methacrylate) ended 7-hydroxy coumarin; (b) PMMA 7-chloracetoxyloxy coumarin ended (CAPMMA); (c) P(BMA-b-MMA-b-BMA) dual lacton functionalized diblock copolymer; (d) Miktoarm star shaped P[(BMA-b-MMA-b-BMA)-co-( $\varepsilon-\mathrm{CL})]$.<smiles>C=C(C)C(=O)OCc1ccccc1</smiles>

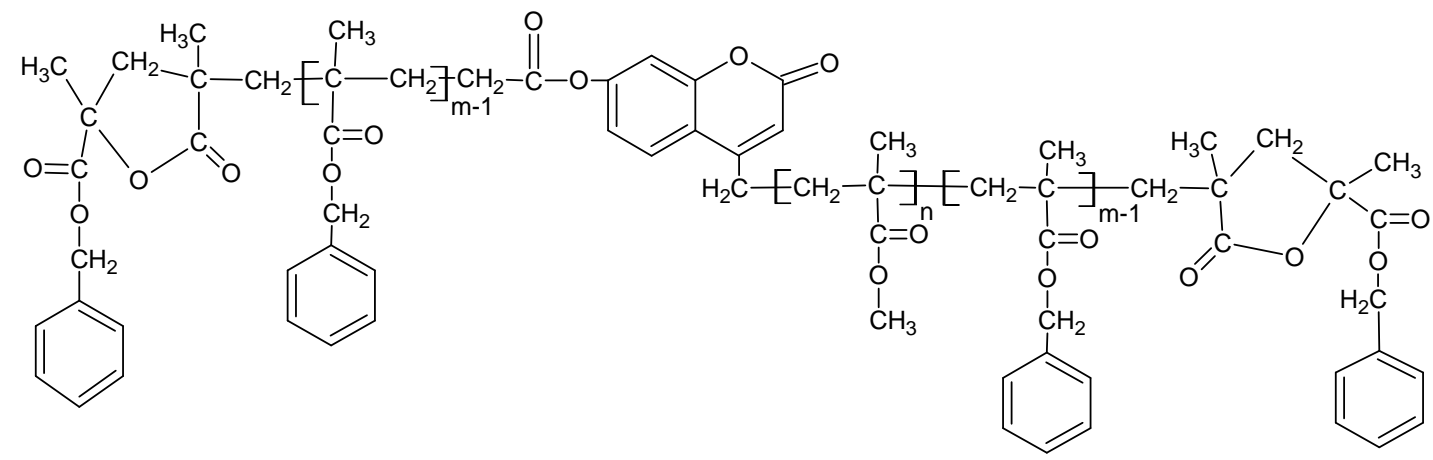

Scheme 4. The reaction of P(BMA-b-MMA-b-BMA) dual functionalized diblock copolymer. 


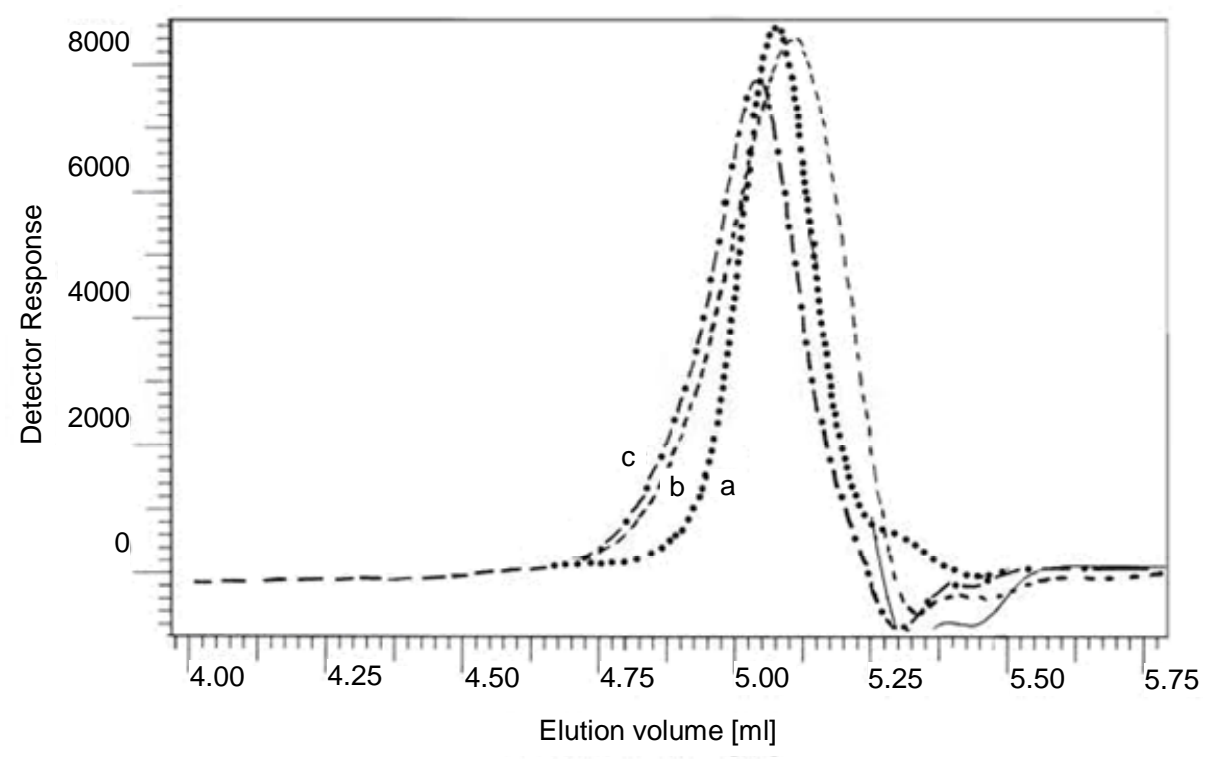

Figure 5. GPC curves of (a) P(BMA) ended lacton; (b) Miktoarm star shaped P(BMA-co- $\varepsilon-C L)$; (c) Three armed P( $\varepsilon$-CL).

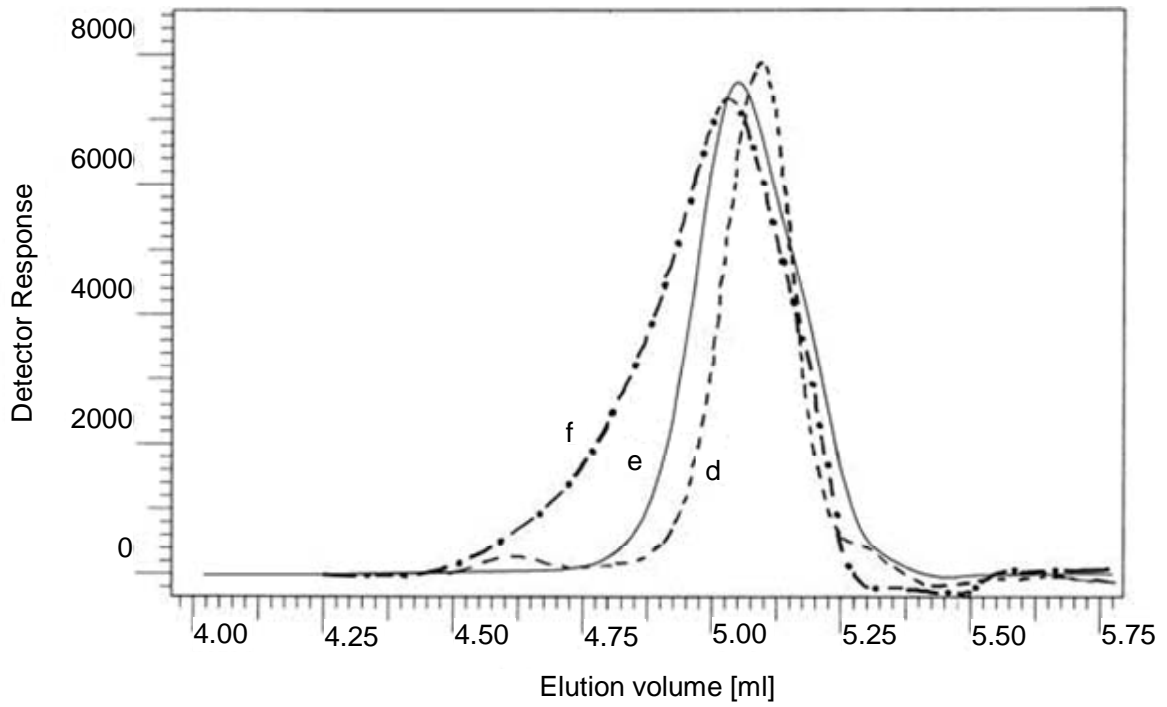

Figure 6. GPC curves of (d) PMMA ended 7-hydroxy coumarin; (e) P(BMA-b-MMA-b-BMA) dual lacton functionalized diblock copolymer; (f) Miktoarm star shaped P[(BMA-b-MMA-b-BMA)-co-( $\varepsilon-C L)]$.

The $M_{n, \mathrm{NMR}}$ value of poly(BMA) ended lacton wes estimated from the ratio of the methylene (b) and terminal one (a). The $M_{n, \mathrm{NMR}}$ value (2900) was close to $M_{n, \mathrm{GPC}}$ (3050) (Table 1). That of poly(BMA-co- $\varepsilon$-CL) mictoarm star shaped (f curve in Figure 6) was 8600 and its polydispersity was 1.24 . According to ${ }^{1} \mathrm{H}-\mathrm{NMR}$ (b in Figure 2), $\varepsilon$-PCL composition in the well-defined mictoarm star-shaped P(BMA-co- $\varepsilon$-CL) with terminal hydroxyl group was $89.5 \%$ (by mol). The $M_{n, \mathrm{NMR}}$ value of $\varepsilon$-PCL in three-armed P(BMA-co- $\varepsilon$-CL) was estimated from the ratio of the methylene proton (c) and terminal one (d). Integration heights of c is $200 \mathrm{~mm}$, that of $\mathrm{d}$ is 4 . So, $M_{n, \mathrm{NMR}}$ value of PCL in copolymer is 5700 . The peaks made it possible to evaluate the polymerization degree of PCL in copolymer. The value $n \mathrm{CL}=16$ means that contain CL unit per arm. The Mn, GPC value of three armed poly $(\varepsilon-C L)$ (e curve in Figure 6) prepared under synthesis conditions of miktoarm star shaped $\mathrm{P}(\mathrm{BMA}-\mathrm{co}-\varepsilon-\mathrm{CL})$. This means that contain $29 \mathrm{CL}$ units per arm. Decreasing the polymerization degree of PCL in copolymer is as a result of being difficult in ring open of lac- ton group.

To preapare poly(BMA-b-MMA- $b$-BMA) dual lacton functionalized was used poly(MMA-b-BMA) ended 7-chloroacetyloxy coumarin. Figure 6 shows the typical GPC curves of poly(MMA-b-BMA) ended 7-hydroxy 
Table 1. GPC data of polymers.

\begin{tabular}{lcc}
\hline Polymer & $\boldsymbol{M}_{\boldsymbol{n}}$ & $\boldsymbol{H I}\left(=\boldsymbol{M}_{\mathrm{w}} / \boldsymbol{M}_{\boldsymbol{n}}\right)$ \\
\hline P(BMA) ended lacton & 2900 & 1.20 \\
Miktoarm star shaped P(BMA-co- $\varepsilon$-CL) & 8600 & 1.24 \\
Star shaped P( $\varepsilon$-CL) & 10,000 & 1.20 \\
$\begin{array}{l}\text { PMMA ended 7-hydroxy coumarin } \\
\text { P[(BMA-b-MMA- } b \text {-BMA) }\end{array}$ & 4000 & 1.10 \\
$\begin{array}{l}\text { dual functionalized } \\
\begin{array}{l}\text { Miktoarm star shaped } \\
\text { P[(BMA-b-MMA- } b \text {-BMA)-co-( }(\varepsilon-C L)]\end{array}\end{array}$ & 8900 & 1.15 \\
\hline
\end{tabular}

coumarin (d curve in Figure 6), poly(BMA-b-MMA$b$-BMA), macromonomer, dual lacton functionalized (e curve in Figure 6) and mictoarm star shaped poly(BMAb-MMA-b-BMA)-co- $\varepsilon$-CL (f curve in Figure 6). The $M_{n, \mathrm{GPC}}$ value of poly(MMA-b-BMA) ended 7-chloroacetyloxy coumarin was 4000 and $M_{w} / M_{n}$ is 1,1 . That of poly(BMA-b-MMA- $b$-BMA) dual lacton functionalized was 8900 and polydispersity was 1.15 . The polymerization degree of BMA, MMA and BMA in macromonomer dual lacton functionalized was 14:100:14, respectively. The GPC results were summarized in Table 1. They indicate that in each block copolymer the peak is shifted toward a lower molecular weight region compared with that of its original lineer poly(BMA) with a little change in molecular weight distribution.

\subsection{DSC Measurements}

The glass transition temperatures of poly( $\varepsilon$-caprolacton)(PCL) three armed, miktoarm poly[( $\varepsilon$-caprolacton) ( $\varepsilon$-PCL)-co-benzylmethacrylate(BMA)] three armed, miktoarm poly(BMA-b-MMA-b-BMA) ended dual lacton with coumarin core, poly(MMA) ended 7-hidroxy coumarin and poly(MMA-b-BMA) ended 7-chloroacetyloxy coumarin were measured by DSC. The samples were heated from $20^{\circ} \mathrm{C}$ to $200^{\circ} \mathrm{C}$ at a rate of $20^{\circ} \mathrm{C} / \mathrm{min}$. Representative DSC curves of the polymers were shown in Figure 7. The melting point of poly( $\varepsilon$-caprolacton) (PCL) three armed was measured at $59.5^{\circ} \mathrm{C} \mathrm{(a} \mathrm{in} \mathrm{Figure}$ 7). In case of miktoarm star shaped poly[( $\varepsilon$-caprolacton) (PCL)-co-benzyl methacrylate(BMA)] (b in Figure 7) is $62.5^{\circ} \mathrm{C}$. The increasing in this temperature means that BMA units in copolymer influences the crystallinity of PCL. The $T_{g}$ of the lineer poly(BMA) prepared by ATRP method is $54^{\circ} \mathrm{C}$ [22] and is lower than the $T_{m}$ of PCL. But not observing of $T_{g}$ for the poly(BMA) with amorphous character is due to overlap with the peak area of $T_{m}$ for poly $[(\varepsilon$-caprolacton)(PCL)-co-benzyl methaylate (BMA)]. The poly(BMA-b-MMA- $b$-BMA) ended dual lacton with coumarin core (c in Figure 7) bearing MMA, BMA and $\mathrm{CL}$ units showed only a $T_{m}$ at $66.9^{\circ} \mathrm{C}$.

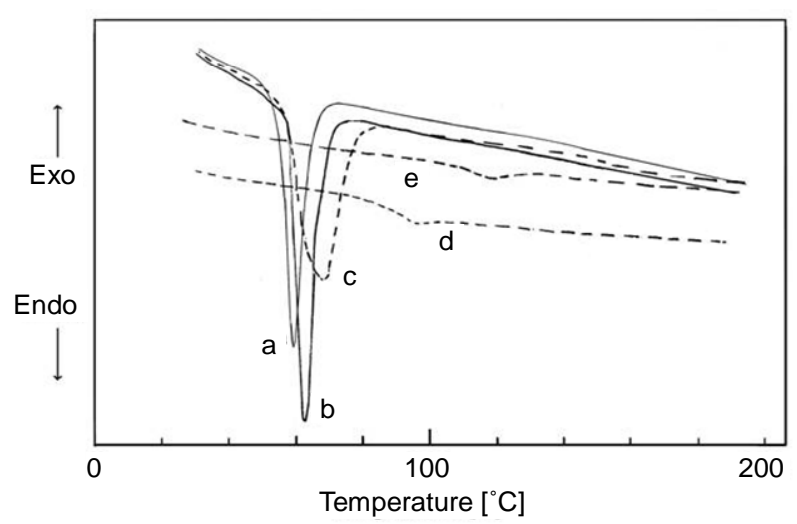

Figure 7. DSC curves of (a) Three armed P( $\varepsilon-C L)$; (b) Miktoarm star shaped P(BMA-co- $\varepsilon-C L)$; (c) Miktoarm star shaped P[(BMA-b-MMA-b-BMA)-co-( $\varepsilon-C L)]$; (d) P(BMA-bMMA-b-BMA) dual lacton functionalized diblock copolymer; (e) PMMA 7-chloracetoxyloxy coumarin ended.

Although the $T_{g}$ of the PMMA block is higher than the $T_{m}$ of PCL block, $T_{g}$ of PMMA is not observed. This is propably due to solubilization of PMMA amorphous blocks within PCL liquid phase melting at $66.9^{\circ} \mathrm{C}$. The $T_{g}$ of PMMA 7-chloracetoxyloxy coumarin ended used in synthesis of poly(BMA-b-MMA- $b$-BMA) ended dual lacton with coumarin core was measured as $83^{\circ} \mathrm{C}$ by DSC. This temperature is between that of BMA and MMA homopolymers and it is showing a single phase behavior. Most of the polymers having relatively low molecular weight are generally compatible [30].

\subsection{Thermogravimetric Studies of the Polymers}

Thermal studies of miktoarm star shaped poly[(BMA$\varepsilon$-CL)] and poly(MMA) ended 7-hydroxy coumarin, poly (MMA) ended 7-chloroacetyloxy coumarin and poly (BMA-b-MMA- $b$-BMA) ended dual lacton with coumarin core were investigated by thermogravimetric analysis. The thermogravimetric curves of polymers measured between room temperature to $500^{\circ} \mathrm{C}$ at a heating rate of 10 ${ }^{\circ} \mathrm{C} / \mathrm{min}$ under nitrogen flow are shown in Figure 8 in comparison with those of poly[( $\varepsilon$-caprolacton)(PCL), poy(BMA) ended lacton by ATRP method. In general, the polymers showed a thermal degradation with a two stages. For first stage, the miktoarm star shaped $\mathrm{P}(\varepsilon-\mathrm{CL}$ co-BMA) (b curve in Figure 8) decomposes at $235^{\circ} \mathrm{C}$. The second stage, that is, more rapid weight loss random chain scission and depolymerization to BMA starts at $320^{\circ} \mathrm{C}$. While poly $(\varepsilon$-caprolacton) three armed (e curve in Figure 8) decomposes at $310^{\circ} \mathrm{C}$, linear poly(BMA) ended lacton prepared by ATRP method starts at $150^{\circ} \mathrm{C}$. Thus, $\mathrm{P}(\varepsilon$-CL-co-BMA) three armed decomposes (at $230^{\circ} \mathrm{C}$ ) between those of homopolymers with both units. As was seen, b curve in Figure 8, while thermal stability of poly (( $\varepsilon$-CL-co-BMA) observes lower than that of poly (BMA-b-MMA-b-BMA) ended dual lacton with cou- 
marin (a curve in Figure 8) core to $317^{\circ} \mathrm{C}$, that of miktoarm star shaped $\mathrm{P}(\varepsilon$-CL-co-BMA) three armed after it temperature increases with a important different. This propably results in depolymerization of MMA block in poly(BMA-b-MMA- $b$-BMA). Poly(MMA) prepared by free radical method in this study decomposes in a single stage at about $272^{\circ} \mathrm{C}$, but that poly(MMA) ended 7-hydroxy coumarin (c curve in Figure 8) decomposes at the first stage between 292 and $420^{\circ} \mathrm{C}$ by $97 \%$ weight loss, and it may be result in that coumarin group retards depolymerization tendency of PMMA ended 7-hydroxy coumarin in comparison that of poly(MMA) prepared by free radical polymerization method. Poly(MMA) ended 7-hydroxy coumarin (c curve in Figure 8) decomposes at the first stage between $292^{\circ} \mathrm{C}$ and $420^{\circ} \mathrm{C}$ by $97 \%$ weight loss. The initial decomposition temperature or stabilitiy of miktoarm star shaped P[(BMA-b-MMA- $b$-BMA)-co$(\varepsilon-C L)]$ (d curve in Figure 8) is higher in comparison to the other copolymers. It means that the MMA and $\varepsilon$-CL moities delay chain scissions and volatile during degradation of miktoarm star shaped P[(BMA-b-MMA- $b$ BMA)-co- $(\varepsilon-\mathrm{CL})]$ from ambient temperature to $500^{\circ} \mathrm{C}$. The thermal stability of this polymer are considerably different than that of poly(MMA) prepared by free radical method [31]. Some thermal degradation characteristics of polymers are summarized in Table 2 .

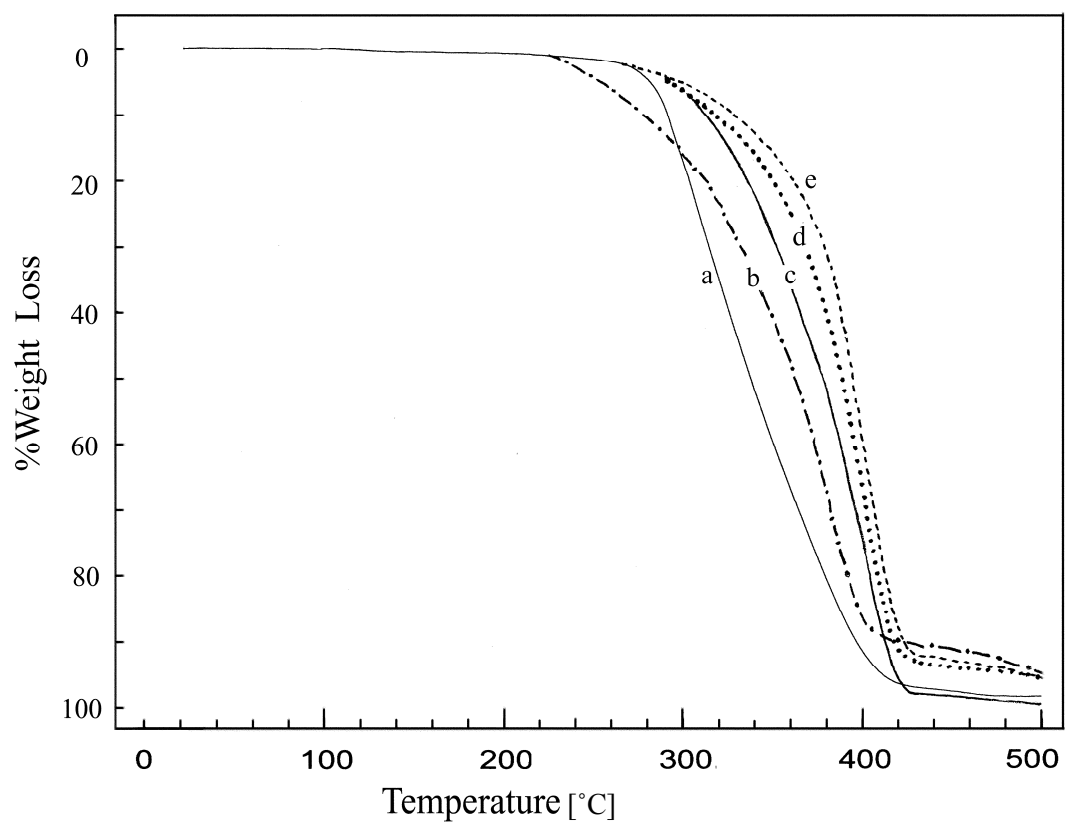

Figure 8. TGA curves of (a) P(BMA-b-MMA-b-BMA) dual lacton functionalized diblock copolymer; (b) Miktoarm star shaped poly(BMA); (c) Poly(methyl methacrylate) ended 7-hydroxy coumarin; (d) Miktoarm star shaped P(BMA-b-MMA-bBMA)-co-( $\varepsilon-C L)] ;(e)$ Three armed P( $\varepsilon$-CL).

Table 2. TGA data for some degradation characteristic of miktoarm star poly[ $\varepsilon$-CL-co-benzyl methacrylate (BMA)], poly ( $\varepsilon$-caprolacton)(PCL) three armed and their copolymers.

\begin{tabular}{|c|c|c|c|c|c|}
\hline Polymer & ${ }^{\mathrm{a}} T_{i}\left({ }^{\circ} \mathrm{C}\right)$ & ${ }^{\mathrm{b}} T_{\% 50}\left({ }^{\circ} \mathrm{C}\right)$ & $\%$ Weight Loss at $300^{\circ} \mathrm{C}$ & $\%$ Weight Loss at $350^{\circ} \mathrm{C}$ & $\%$ Residue at $400^{\circ} \mathrm{C}$ \\
\hline PBMA ended lacton [22] & 150 & 250 & 25 & 61 & 12.0 \\
\hline Miktoarm star shaped $\mathrm{P}(\varepsilon$-CL-co-BMA) & 230 & 370 & 15 & 36 & 12.0 \\
\hline $\begin{array}{l}\mathrm{P}(\mathrm{BMA}-\mathrm{b}-\mathrm{MMA}-b \text {-BMA) dual lacton } \\
\text { functionalized diblock copolymer }\end{array}$ & 250 & 397 & 3 & 16 & 43.0 \\
\hline PMMA ended 7-hydroxy coumarin & 292 & 321 & 18 & 59 & 9.0 \\
\hline $\begin{array}{l}\text { Miktoarm star shaped } \\
\text { P[(BMA-b-MMA- } b \text {-BMA)-co- }(\varepsilon-\mathrm{CL})]\end{array}$ & 295 & 400 & 3 & 28 & 23.5 \\
\hline $\mathrm{P}(\varepsilon$-CL $)$ three armed & 310 & 384 & - & 22 & 30.0 \\
\hline
\end{tabular}

${ }^{\mathrm{a}}$ Initial decomposition temperature; ${ }^{\mathrm{b}}$ Decomposition temperature at $50 \%$ weight loss. 


\section{Conclusion}

In this paper, it was carried out synthesis of miktoarm star copolymers using "core-first" method by ring-opening (ROP) process using appropriate (co)polymers with poly(benzyl methacrylate) lacton functionalized and P(BMA-b-MMA- $b$-BMA) dual functionalized diblock copolymer as macromonomer. Low-molecular-weight poly(benzyl methacrylate) one and P(BMA-b-MMA- $b$ BMA) dual functionalized diblock copolymer prepared by atom transfer radical polymerization (ATRP) of benzyl methacrylate at $110^{\circ} \mathrm{C}$ was used as starting materials for ring open polymerization. Then, the ROP of $\varepsilon$-caprolacton with one and dual functionalized macromonomers was carried out in the presence of tin(II)bis(2-ethylhexanoate) $\left(\mathrm{Sn}(\mathrm{Oct})_{2}\right)$ at $130^{\circ} \mathrm{C}$. Although poly(benzyl methacrylate) ended lactone with $\varepsilon$-caprolacton shows ring open polymerization in presence of phloroglucin by $\mathrm{Sn}(\mathrm{Oct})_{2}$, poly(benzyl methacrylate) lactone ended did not show ring opening reaction under conditions above mentioned.

\section{Acknowledgements}

The authors wish to thank the Firat University Research Fund for financial support of this Project (FUBAP-1650) and M. Fatih Coskun, who provided chromatograms (GPC) at our university.

\section{REFERENCES}

[1] H. Iatrou and H. N. Hadjichristidis, "Synthesis of a Model 3-Miktoarm Star Terpolymer," Macromolecules, Vol. 25, No. 18, 1992, pp. 4649-4651. doi:10.1021/ma00044a028

[2] T. He, D. Li, X. Sheng and B. Zhao "Synthesis of ABC 3-Miktoarm Star Terpolymers from a Trifunctional Initiator by Combining Ring-Opening Polymerization, Atom Transfer Radical Polymerization, and Nitroxide-Mediated Radical Polymerization," Macromolecules, Vol. 37, No. 9, 2004, pp. 3128-3135. doi:10.1021/ma036010c

[3] P. J. Shi, Y. G. Li and C. Y. Pan, "Block and Star Block Copolymers by Mechanism Transformation X. Synthesis of Poly(Ethylene Oxide) Methyl Ether/Polystyrene/Poly (L-Lactide) ABC Miktoarm Star Copolymers of by Combination of RAFT and ROP," European Polymer Journal, Vol. 40, No. 7, 2004, pp. 1283-1290. doi:10.1016/j.eurpolymj.2004.02.024

[4] S. Sioula, N. Hadjichristidis and E. L. Thomas, "Direct Evidence for Confinement of Junctions to Lines in an 3 Miktoarm Star Terpolymer Microdomain Structure," Macromolecules, Vol. 31, No. 23, 1998, pp. 8429-8432. doi:10.1021/ma980622t

[5] S. Pispas, N. Hadjichristidis, I. Potemkin and A. Khokhlov, "Effect of Architecture on the Micellization Properties of Block Copolymers: $\mathrm{A}_{2} \mathrm{~B}$ Miktoarm Stars vs. AB Diblocks," Macromolecules, Vol. 33, No. 5, 2000, pp. 1741-1746. doi:10.1021/ma991636h

[6] J. Rieger, O. Coulembier, P. Dubois, K. V. Bernaerts, F. E. Du Prez, R. Jerome and C. Jerome, "Controlled Syn- thesis of an ABC Miktoarm Star-Shaped Copolymer by Sequential Ring-Opening Polymerization of Ethylene Oxide, Benzyl $\beta$-Malolactonate, and $\varepsilon$-Caprolactone," $M a$ cromolecules, Vol. 38, No. 26, 2005, pp. 10650-10657. doi:10.1021/ma0515811

[7] X. Zhang, J. Xia and K. Matyjaszewski, "End-Functional Poly(Tert-butyl Acrylate) Sta Polymers by Controlled Radical Polymerization," Macromolecules, Vol. 33, No. 7, 2000, pp. 2340-2345. doi:10.1021/ma991076m

[8] J. P. Kennedy and S. Jacob, "Cationic Polymerization Astronomy. Synthesis of Polymer Stars by Cationic Means," Accounts of Chemical Research, Vol. 31, No. 12, 1998, pp. 835-841. doi:10.1021/ar950065k

[9] K. Ohno, B. Wong and D. M. Haddleton, "Synthesis of Well-Defined Cyclodextrin-Core Star Polymers," Journal of Polymer Science Part A: Polymer Chemistry, Vol. 39, No. 13, 2001, pp. 2206-2214.

[10] A. M. Kasko, A. M. Heintz and C. Pugh, "The Effect of Molecular Architecture on the Thermotropic Behavior of Poly[11-(4'-cyanophenyl-4"'-phenoxy)undecyl acrylate] and Its Relation to Polydispersity," Macromolecules, Vol. 31, No. 2, 1998, pp. 256-271. doi:10.1021/ma971279f

[11] G. Ravikumar and R. D. Chakraborty, "Environmentally Benign Process For Bulk Ring Opening Polymerization of Lactones Using Iron and Ruthenium Chloride Catalysts," Journal of Molecular Catalysis A: Chemical, Vol. 301, No. 1-2, 2009, pp. 84-92. doi:10.1016/j.molcata.2008.11.010

[12] F. Deng, K. S. Bisht, R. A. Gross and D. L. Kaplan, "Chemoenzymatic Synthesis of a Multiarm Poly(Lactideco-epsilon-caprolactone)," Macromolecules, Vol. 32, No. 15, 1999, pp. 5159-5161. doi:10.1021/ma990055p

[13] M. Trollsas and J. L. Hedrick, "Dendrimer-Like Star Polymers," Journal of the American Chemical Society, Vol. 120, No. 19, 1998, pp. 4644-4651. doi: $10.1021 / \mathrm{ja} 973678 \mathrm{w}$

[14] H. R. Kricheldorf, "Syntheses and Application of Polylactides," Chemosphere, Vol. 43, No. 1, 2000, pp. 49-54. doi:10.1016/S0045-6535(00)00323-4

[15] K. E. Uhrich, S. M. Cannizzaro, R. S. Langer and K. M. Shakesheff, "Polymeric Systems for Controlled Drug Release," Chemical Reviews, Vol. 99, No. 11, 1999, pp. 3181-3198. doi:10.1021/cr940351u

[16] F. G. Hutchinson and B. J. A. Furr, "Biodegradable Polymer Systems for the Sustained Release of Polypeptides," In: A. H. Fawcett, Ed., High Value Polymers, The Royal Society of Chemistry, Cambridge, 1991, pp. 58-78

[17] B. S. Lele and J. C. Leroux, "Synthesis of Novel Amphiphilic Star-Shaped Poly(Epsilon-caprolactone)-block-poly (N-(2-hydroxypropyl)methacrylamide) by Combination of Ring-Opening and Chain Transfer Polymerization," Polymer, Vol. 43, No. 21, 2002, pp. 5595-5606. doi:10.1016/S0032-3861(02)00435-4

[18] J. Chen, H. Zhang, J. Chen and X. Wang, "Synthesis of Star-Shaped Poly(epsilon-caprolactone)-B-poly(styrene) Block Copolymer by Combining Ring-Opening Polymerization And Atom Transfer Radical Polymerization," Journal of Macromolecular Science, Part A: Pure and Applied Chemistry, Vol. 42, No. 9, 2005, pp.1247-1257. doi:10.1080/10601320500189554

[19] J. L. Hedrick, M. Trollsas, C. J. Hawker, B. Atthoff, H. Claesson, A. Heise, R. D. Miller, D. Mecerreyes, R. Jerome and P. Dubois, "Dendrimer-Like Star Block and 
Amphiphilic Copolymers by Combination of Ring Opening and Atom Transfer Radical Polymerization," Macromolecules, Vol. 31, No. 25, 1998, pp. 8691-8705. doi:10.1021/ma980932b

[20] R. F. Storey and J. W. Sherman, "Characterization of Polyisobutylene by Matrix-Assisted Laser Desorption Ionization Time-of-Flight Mass Spectrometry," Macromolecules, Vol. 35, No. 5, 2002, pp. 1505-1512.

[21] A. Kowalski, A. Duda and S. Penczek, "Kinetics and Mechanism of Cyclic Esters Polymerization Initiated with Tin (II) Octoate, 1. Polymerization of Epsilon-Caprolactone," Macromolecular Rapid Communications, Vol. 19, No. 11, 1998, pp. 567-572. doi:10.1002/marc.1998.030191106

[22] K. Demirelli, C. Coskun and E. Kaya, "Polymers Based on Benzyl Methacrylate: Synthesis via Atom Transfer Radical Polymerization, Characterization, and Thermal Stabilities," Journal of Polymer Science Part A: Polymer Chemical, Vol. 42, No. 23, 2004, pp. 5964-5973. doi:10.1002/pola.20447

[23] L. Santana, M. Teijeira, E. Uriarte, C. Teran, B. Liñares, R. Villar, R. Laguna and E. Cano, "AM1 Theoretical Study, Synthesis and Biological Evaluation of Some Benzofuran Analogues of Anti-Inflammatory Arylalkanoic Acids," European Journal of Pharmaceutical Sciences, Vol. 7, No. 2, 1999, pp. 161-166. doi:10.1016/S0928-0987(98)00019-0

[24] G. Cheng, P. F. W. Simon, M. Hartenstein and A. H. E. Muller, "New Strategy for the Synthesis of Halogen-Free Acrylate Macromonomers by Atom Transfer Radical Polymerization," Macromolecules, Vol. 34, No. 16, 2001, pp. 5394-5397. doi:10.1021/ma010277z

[25] C. Y. Hong and C. Y. Pan, "Synthesis and Characterization of Hyperbranched Polyacrylates in the Presence of a Tetrafunctional Initiator with Higher Reactivity Than Monomer by Self-Condensing Vinyl Polymerization,"
Polymer, Vol. 42, No. 23, 2001, pp. 9385-9391. doi:10.1016/S0032-3861(01)00494-3

[26] J. Nijenhuis, D. W. Grijpma and A. J. Pennings, "Lewis acid-Catalyzed Polymerization of L-Lactide. Kinetics and Mechanism of the Bulk-Polymerization," Macromolecules, Vol. 25, No. 24, 1992, p. 6419. doi:10.1021/ma00050a006

[27] H. R. Kricheldorf, I. Kreiser-Saunders and C. Boettcher, "Polylactones: 31. Sn(II)octoate-initiated Polymerızation of L-Lactide: A Mechanistic Study," Polymer, Vol. 36, No. 6, 1995, pp. 1253-1259. doi:10.1016/0032-3861(95)93928-F

[28] P. J. A. In’t Veld, E. M. Velner, P. van de Witte, J. Hamhuis, P. J. Dijkstra and J. Feijen "Melt Block Polymerization of $\varepsilon$-Caprolactone and L-Lactide," Journal of Polymer Science Part A: Polymer Chemistry, Vol. 35, No. 2, 1997, pp. 219-226.

[29] K. Majerska, A. Duda and S. Penczek, "Kinetics and Mechanism of Cyclic Esters Polymerisation Initiated with Tin(II) Octoate, 4. Influence of Proton Trapping Agents on the Kinetics of Epsilon-Caprolactone and L,L-Dilactide Polymerisation," Macromolecular Rapid Communications, Vol. 21, No. 18, 2000, pp. 1327-1332. doi:10.1002/1521-3927(20001201)21:18<1327::AID-MA RC1327>3.0.CO;2-9

[30] E. Nolley, J. W. Barlow and D. R. Paul, "Mechanical Properties of Polypropylene-Low Density Polyethylene Blends," Polymer Engineering and Science, Vol. 20, No. 5, 1980, pp. 364-369. doi:10.1002/pen.760200508

[31] M. F. Coşkun, K. Demirelli and M. Coşkun, "Homo- and Copolymerization of Phenacyl Methacrylate via the Atom Transfer Radical Polymerization Method," Journal of Polymer Science Part A: Polymer Chemical, Vol. 44, No. 9, 2007, pp. 995-1004. 